\title{
Propositional attitude, affective attitude and irony comprehension
}

\author{
Francisco Yus \\ University of Alicante
}

\begin{abstract}
According to relevance theory, irony comprehension invariably entails the identification of some opinion or thought (echo) and the identification of the speaker's dissociative attitude. In this paper, it is argued that it is also essential for hearers to identify not only that propositional attitude, but also the affective attitude that the speaker holds towards the source of this echo, so that an optimally relevant interpretive outcome is achieved. The term comprises feelings and emotions of a non-propositional quality which affect the propositional effects obtained in ironical communication. The paper further argues for the need to incorporate non-propositional effects to the traditional propositional object of pragmatic research.
\end{abstract}

Keywords: irony, relevance theory, propositional attitude, affective attitude, feelings, emotions, metarepresentation

\section{Relevance-theoretic research on irony}

Sperber and Wilson's (1995) relevance theory (henceforth RT) makes very specific claims on what is at stake in irony comprehension. Beyond the traditional (and often inaccurate) approach to irony as communicating the opposite of what is literally stated, RT focuses on the fact that irony necessarily needs an opinion, norm, thought or utterance (echo) to which a dissociative attitude is held. Specifically, for Sperber and Wilson (1995: 240) the recovery of irony-related implicatures depends, apart from a recognition of the utterance as echoic, on an identification of the source of the opinion echoed and on a recognition that the speaker's attitude to the opinion echoed is one of rejection or disapproval (dissociative attitude). These two essential elements will be sketched below.

\subsection{Dissociative attitude}

Irony necessarily entails a dissociative attitude, that is, a negative attitude of disapproval or rejection towards some thought or opinion that the utterance makes manifest. An often cited example is that of someone inviting a friend to go to the beach and insisting that the weather is going to be fine, and upon arriving at the beach it stars pouring down. By saying "Nice weather we're having!" the speaker does not want to assert that it is inappropriate to say that the weather is fine when it is actually pouring down, but to dissociate himself/herself from his/her friend's opinion (and utterance) that the weather would be fine and that there was no reason not to go to the beach. Actually, ironies make little sense if this attitude is not spotted, that is, there is little interest in simply communicating the opposite to what is stated literally (in this case, it is obvious that the weather is not fine, so why say the opposite of what is the case?). The interest lies, rather, in the speaker's attitude to an echoed thought or opinion.

Other examples are provided in Yus (2016). Firstly, when someone says to his son "Well done! after he has lost 6-0 6-0 in a tennis match, he is probably not so much interested in communicating that his son played badly, which is pretty obvious (especially to his son), but to show that his game did not live up to his expectations and that he dissociates himself from these previous expectations; or perhaps he dissociates himself from his son's previous utterance: "This time I am going to win the match!". Secondly, to say, after a very unfortunate meeting, "That went well!" is utterly puzzling since it is obvious to both interlocutors that the outcome of the meeting was anything but positive. In this case, the main point of the utterance is not to communicate the opposite proposition ("The meeting didn't go well"), as 
traditional approaches to irony would claim. RT would instead stress that the main point is to dissociate oneself from a thought (e.g. a hope, desire, expectation that the meeting would go well) or utterance (e.g. his previous utterance, just before entering the room, for example "The meeting's going to be fine!").

\subsection{Echo}

Besides the speaker's dissociative attitude, a necessary element of irony is the need of a source for the echo. In short, the thought involved in ironic communication must be attributed to some actual person, or the speaker in a different context or humans in general, so that the underlying attitude is clearly ascribable as dissociative and not as that of endorsement or support. The notion of echo is intentionally broad, since it covers direct echoes of previous utterances, and also echoes of attributed thoughts (real or imaginary), norms and expectations. Therefore, in all ironies we should be able to trace the echo involved. As Wilson (2013: 46) summarises, the thought being echoed need not have been overtly expressed in an utterance: it may be an unexpressed belief, hope, wish or norm-based expectation. The source of the thought may be a specific person, a type of person, or people in general; and it is only when the source is a specific person or type of person that the irony will have a definite target or victim.

Sperber and Wilson (1995: 239-240) exemplify this need of echo with Mary's comment in (1), which obviously aims to communicate (2), but whose main point is rather to communicate ironical implicatures such as the ones listed in (3) (now adapted and extended), all of which demand from Peter the identification of the utterance as echoic (and Mary's attitude involved as dissociative):

(1) Peter: It's a lovely day for a picnic.

[They go for a picnic and it rains].

Mary [sarcastically]: It's a lovely day for a picnic, indeed.

(2) Mary manifestly believes that it is not a lovely day for a picnic.

(3) It was wrong of Peter to say that it was a lovely day for a picnic.

Peter's judgement has been unsound.

It was Peter's fault that their day has been ruined.

Mary should never have trusted Peter in his weather prediction.

As is commented upon in Yus (2016a), the fact that all ironical utterances are echoic does not mean that the source of the echo is always easily traceable. Sperber and Wilson (1981: 310) acknowledge the broad elements that can be accounted for under the label of echo: "Some are immediate echoes, and others delayed; some have their source in actual utterances, others in thoughts or opinions; some have a real source, others an imagined one; some are traceable back to a particular individual, whereas others have a vaguer origin".

\section{Feelings, emotions and impressions (affective attitude)}

The main claim in this paper is that, for an appropriate account of irony, it is not enough to analyse it in terms of dissociative propositional attitudes and identification of the echo, but the identification of the speaker's feelings and emotions (under the broad label of affective attitude) toward the source of the echo is also essential. Indeed, ironical interpretations differ radically depending on what affective attitude is held by the speaker when uttering the irony, and that affective attitude may not only influence the eventual choice of an interpretation, but also the very ascription of irony as utterly offensive, mildly offensive, praising or humorous 
(see below).

Affective attitude will be regarded as an intentional state with a referent. In the same way as Hess (2001) qualifies emotions as intentional states (even if sometimes they are produced beyond conscious control), affective attitudes may also be regarded as intentional states in the sense that they may be intentionally elicited and inferred as such. ${ }^{1}$ Indeed, we are not angry or surprised in general, but we are angry or surprised at something, which constitutes the object of the affective attitude. In this paper, it will be proposed that the object of affective attitude is the source of the echo towards which a dissociative attitude is held.

As has already been proposed, feelings and emotions will be brought under the umbrella term of affective attitude, but studies abound differentiating these terms, often without agreement on their boundaries. ${ }^{2}$ For the purposes of this paper, though, it will suffice to say that these phenomena share their non-propositional status and the fact that they alter, to a greater or lesser degree, the eventual (propositional) interpretation of the utterance to which they are attached. Certainly, the research on feelings and emotions is vast, but my interest lies in the way their production influences the inferential outcome of propositional content, as is clearly the case of affective attitudes during ironical communication.

Another issue to bear in mind for an analysis of irony is the accuracy of affective attitude ascription when utterances are interpreted, and there is currently a debate over whether humans possess an ability to infer subtle types and intensities of feelings or emotions from communicative behaviour. For example, Planalp (1999: 45) suggests that people can recognise emotion in each other's voices much better than we would expect, with anger, sadness, and boredom being the most recognisable ones, followed by joy and fear, and with disgust and shame barely recognisable. By contrast, Fussell (2002: 2) remarks that paralinguistic and nonverbal channels are insufficient for expressing the full range of human emotional experiences. A reason is that nonverbal cues can only indicate what general class of emotions a person is feeling, not detailed information about that person's emotional state: "By seeing that someone is crying, for instance, we might assume that they are sad; by the extent of sobbing we might even be able to infer the intensity of the sadness. But the tears in and off themselves provide no information about the particular experience of sadness". Similarly, Olsson and Ochsner (2007: 65) comment that emotion understanding is not a simple inferential task, because nonverbal cues to emotion are often ambiguous. In the analysis of affective attitude in irony comprehension, my opinion is that humans are good enough at discriminating at least broad degrees and intensities of affective attitudes, to the extent that radically different interpretive outcomes may be generated out of this ascription, as will be exemplified below. In any case, variations can be found in how fine-grained the ascription is. As Strey (2016: 78-79) summarises, in emotional communication what is conveyed is an array of affective effects, and one may identify which emotions are being expressed or only grasp a sense that some emotion is present in that piece of communication.

1. I would like to thank a reviewer of this paper for reminding me of the fact that many emotions are not typically regarded as intentional in the traditional sense of the word. They are often described as organised psycho-physiological reactions, involving rapid onset and automatic appraisal, etc. Though it is generally acknowledged that emotions have cognitive content and involve cognitive appraisal of that content (i.e. they are about something), the reviewer is right in pointing out that not all emotions can be labelled intentional.

2. For example, Caffi and Janney (1994: 327) differentiate: feelings (broad, complex class of subjective personal sensations or states of inner physiological arousal); emotions (a restricted subset that are relatively transitory, of a certain intensity, and are attached to, or triggered by, particular objects, ideas, or outer incentive events; moods (of longer duration than emotions); attitudes (transitory feeling states with partly uncontrollable subconscious psychobiological components and partly controllable expressive components; and affect (feeling states that are ascribed to others on the basis of their observable behaviour in different situations). Similarly, Strey (2016: 80) distinguishes impressions (an array of propositions, weakly communicated) from emotions (an array of affective cognitive effects). 
Strey (ibid.) correctly remarks that "affective effects are always indeterminate in some degree. As they are non-propositional and non-conceptual, it is difficult to pin down exactly which emotion is being conveyed and in which degree. Assuming that, it is possible to create a continuum of cases between more determinate and more indeterminate emotional effects".

Final issues that might be of some interest for the analysis of affective attitude include the dichotomies exuded vs. intended, innate vs. cultural and intra-cultural vs. inter-cultural. In this paper, the main focus will be on affective attitudes that will be ascribed mainly on the intentional side, even though one may entertain a certain feeling or emotion without assessing its quality or intensity. However, that feeling or emotion (about which there is little conscious awareness) might anyhow have an impact on irony comprehension. Besides, the focus will be on broad, inter-culturally valid affective attitudes.

\section{Propositional attitude, affective attitude and pragmatics}

Traditionally, pragmatics has remained "on the safe side" by analysing the communication of propositions, rather than of feelings, emotions, affective implications, etc. Sperber and Wilson (1995: 57) state that a possible reason is that it is easier to analyse propositions and how inference operates over them. In fact, there seems to be no clear idea of how inference operates over non-propositional objects such as images, impressions or emotions: "Propositional contents and propositional attitudes seem to provide a more solid ground on which to base a partly or wholly inferential approach to communication". The problem is that much of what is communicated does not fit the propositional mould. Pilkington (2000: 164) adds that non-propositional effects would seem to be highly inconvenient phenomena for a pragmatic theory to handle. And Gibbs et al. (2002: 128) further concede that research on intentional communication has traditionally focused on how speakers verbally formulate (and listeners explicitly recover) communicative intentions that can be stated as well-formed propositions. Yet, they acknowledge that in many cases of interpersonal communication, what is important is not so much the propositions explicitly stated or implicated, but the more indeterminate non-propositional meaning and affect that is expressed and understood from communication. Similarly, Bromberek-Dyzman (2012: 84) complains that "language researchers have not developed effective methods to capture the pervasive, yet elusive (nonverbal) affective 'matter' attached to the verbal 'matter'. Even the language repertoire for communicating attitude and affect by a spectrum of explicit and implicit means, is not well understood".

Besides, non-propositional effects are often part of what is overtly intended in the production of an utterance, that is, part of what Sperber and Wilson (2015: 122) have lately called the intended import of the utterance. If, as Moeschler (2009: 456) defines them, nonpropositional effects "result from the interaction between accessible hypotheses or assumptions during the utterance-processing process and other sources of information affecting or causing the mental state of the speaker and/or the hearer", these effects are bound to play a part in the eventual choice of an interpretation and its eventual relevance, and therefore constitute an appropriate object of cognitive pragmatics research.

It should be underlined that RT has indeed accounted for the communication of feelings and emotions, mainly conceptualised as an increased mutual manifestness of a number of assumptions evoking impressions, rather than propositions. As Wharton (2009: 44) summarises, intended non-propositional effects would "bring about a marginal increase in the manifestness of a very wide range of assumptions that are weakly manifest in the cognitive environments ${ }^{3}$ of both communicator and audience, resulting in an increased degree of

3. People construct different concepts and representations of the world, just as their personal experiences are 
similarity or mutuality". An often cited example pictures a woman, Mary, sniffing the air upon arriving at the seaside. When her friend Peter follows suit, there is no one particular good thing that comes to his attention: "the air smells fresh, fresher than it did in town, it reminds him of their previous holidays, he can smell the sea, seaweed, ozone, fish; all sorts of pleasant things come to mind, and while, because her sniff was appreciative, he is reasonably safe in assuming that she must have intended him to notice at least some of them, he is unlikely to be able to pin down her intentions any further" (Sperber and Wilson 1995: 55). In this case, weak implicatures shaped as impressions are at work. Mary probably intended to convey some subset of them, while others will be recovered on Peter's sole responsibility. What we come up with, then, is a continuum of cases, ranging from situations where the speaker's meaning is fully propositional and accountable in terms of explicatures and/or implicatures, to situations where feelings, emotions and impressions generate alterations in the mutuality of assumptions between the interlocutors, with an affective, rather than propositional quality of the eventual relevance obtained (Sperber and Wilson 2015: 122).

Therefore, communication involves the derivation of a number of proposition-related cognitive effects and also weaker, non-propositional affective effects (Strey 2016). Gutt (2013: 6) calls them feeling effects and stresses that the sharing of feelings enhances the relationship between people and, in fact, if feelings are cognitive in nature, they too could arguably be part of the cognitive environment of people. Furthermore, just as understanding the beliefs of others may have important consequences for successful interaction, being aware of their feelings and emotions would seem to be also advantageous, and in fact, as argued in this paper, these affective attitudes can make interpretations differ radically. This view shifts pragmatics beyond the specificity of propositional communication and into a more realistic approach in which speakers convey propositional content (explicit, implicated, propositional attitude) plus feeling- and emotion-related non-propositional effects (affective attitude) whose relevance lies in a certain mutuality, rather than a specific interpretation and which are also relevant even if weaker than fully propositional content:

There is a continuum of cases, from implicatures which the hearer was specifically intended to recover to implicatures which were merely intended to make manifest, and to further modification of the mutual cognitive environment of speaker and hearer that the speaker only intended in the sense that she intended her utterance to be relevant, and hence to have rich, and not entirely foreseeable cognitive effects. (Sperber and Wilson 1995: 201)

Bromberek-Dyzman (2012: 99) also stresses the fact that, on top of propositional meaning, irony communicates non-propositional, implicit, attitude contents. This implicit, evaluative load appears of key significance, worth processing. Communication serves to exchange the contents of our minds, but on top of what we say, we attach attitudes, feelings, moods, to the extent that affective content seems to be the engine of human interaction. The linguistic meaning does not exhaust the communicative potential of non-propositional contents.

This combination of the recovery of intended propositions and the inference of affective states provides, in my opinion, a solid ground upon which the critical, praising or humorous outcome of ironical communication may be explained. Consider these three examples:

[John calls Mary on the phone].

Mary: Hi John! How're things?

John: I am fine! I've just thought... Since Mary is always calling me, today for a

different. This array of information is the individual's cognitive environment, different from person to person. However, some information belonging to the interlocutors' cognitive environments overlaps, the so-called mutual cognitive environment. In ordinary communication interlocutors make predictions of mutuality, that is, of information belonging to this mutual environment. 
change I'll make the call.

Mary: Hahaha. Poor thing... You are right, I should call you more often, but you seem soooo happy to call your friend, don't you? hahaha.

John: Hehehe... Of course, Mary... A pleasure.

[John calls Mary on the phone].

Mary: Hi John! How're things?

John: I am fine! I've just thought... Since Mary is always calling me, today for a change I'll make the call.

Mary: I am sorry... I do call you every now and then... Don't be so angry.

John: Yeah, once a year more or less. I just think I deserve better.

[John calls Mary on the phone].

Mary: Hi John! How're things?

John: I am fine! I've just thought... Since Mary is always calling me, today for a change I'll make the call.

Mary: Hahaha. Poor thing... You are right, I should call you more often, but you seem soooo happy to call your friend, don't you? hahaha.

John: Actually, I am pissed off with having to call you all the time. You could make the effort to call me, couldn't you?

Mary: Oh... I am sorry... Don't be so angry. I never thought you'd be so upset.

In these examples, John has a dissociative attitude towards an opinion echoed, specifically towards a commonsense social norm: that he should not always be the one who calls, and that it would be nice if Mary called him for a change sometimes. However, although the dissociative attitude in (4-6) remains the same, the final interpretation of this echoed opinion varies in each case because of the feelings associated with this opinion (that is, Mary's ascription of John's affective attitude towards the source of the echo). In (4), John does think that it would be nice that Mary called him more often, but the feelings that he holds towards the echoed opinion are on the positive side, and Mary infers his attitudes (dissociative and affective) correctly. The whole exchange is tinged with humour and amusement. By contrast, in (5) John has an attitude of a similar dissociative quality towards the opinion echoed but the feelings that he holds towards that opinion are on the negative side. ${ }^{4}$ Mary, again, correctly locates the echo plus dissociative attitude and also infers that the feelings associated with this echo (John's affective attitude) are negative: John is angry at being the one who has to call her all the time. Hence, she reacts in a different way from the previous example: by apologising. Finally, in (6) the dissociative attitude is correctly inferred but the feelings or emotions associated with the opinion echoed (the affective attitude) are misinterpreted, resulting in an erroneous interactional outcome.

As this combination of attitudes shows, there is no guarantee that a specific case of irony, with a specific dissociative attitude, is invariably going to be interpreted as critical, offensive, praising or humorous, since the variability of the speaker's feelings and emotions (together with contextual constraints) may qualify ironies in radically different terms. For example, Garmendia (2010) proposes the dialogue in (7) as an undoubtedly clear example of critical irony, but it may easily be turned into a positive, non-critical one if the speaker's affective attitude is spotted differently, as can be seen in the alternative continuation of this example suggested in (8) (Yus 2016a: 234):

4. Since "the main claim of the echoic account is that verbal irony is a sub-type of echoic use in which the speaker (generally tacitly) expresses one of a range of dissociative attitudes (scepticism, mockery, rejection, etc.) to a (generally tacitly) attributed utterance or thought" (Wilson 2006: 1730), it is unlikely that John has exactly the same dissociative attitude in examples (4-6), but rather a similar one within a range of dissociative ones. I would like to thank a reviewer of the paper for pointing this out to me. 
(7) When I was looking for something among Ekain's stuff, I found a small box, wrapped as a present. I showed it to him and asked, "What's this?" He put the box back in its place and told me "Nothing; do not open it". Early this morning, Ekain left for a two-week philosophy conference in Ottawa. Without losing a minute, I went to his table and found the small box again. I opened the box and found some beautiful earrings. Some time later, I talked via video-chat with Ekain, and he could see that I was wearing the earrings. He said: "Oh, I see you bought new earrings".

(8) [...] Some time later, I talked via video-chat with Ekain, and he could see that I was wearing the earrings. He said: "Oh, I see you bought new earrings". I replied "Hahaha!!!! Yesssss!!!! Thank you, my dear". Ekain replies with a smile and says "I am glad you like them... You really look gorgeous!!!".

Furthermore, it should be noted that what influences the eventual interpretation of an utterance is not only the identification of the speaker's affective attitude, but also the current feelings and emotions held by the hearer upon inferring the propositional content of the utterance. An example of how the hearer's feelings and emotions may shape and alter the eventual interpretation is provided in Piskorska (2012), in which a husband utters (10) in situation (9):

(9) [A man and a woman are expecting his family for dinner and she is trying to tidy up the dining room. Depending on how messy the room is and how much time she has to tidy it, she will have either positive or negative feelings upon having to do so. He then turns up].

(10) He: I've put the white wine in the fridge.

Under the circumstances in which she has positive feelings about tidying up (i.e. she's not angry), she will infer that he is trying to be helpful and contribute to the organisation of the dinner, implications which are based on premises such as (11a-d). However, if she is angry at having to tidy up the room without much time left, she will infer that he is trying to rush her, or complaining that she is not willing to tidy up, all that based on premises such (11e-i):

(11) a. White wine should be served cold.

b. To serve the wine cold, it is necessary to put it in the fridge some time before serving.

c. One who remembers to put the wine in the fridge is thoughtful and helpful.

d. Drinking lukewarm white can spoil the dinner.

e. Putting wine in the fridge is essential.

f. Cleaning the dining room is not essential.

g. It is important to do essential things when there is little time.

h. There is little time.

i. One who does unnecessary things wastes time.

In any case, the accessibility to any of (11a-i) above is mediated by the woman's feelings and emotions at the time of interpreting the utterance. This also applies to the choice of contextual information used in determining the explicit or implicated interpretation: "Since emotions are generally treated as factors prioritising access to some chunks of information in cognitive processes, they have to be recognized as factors affecting the accessibility of contextual information in comprehension, too" (Piskorska ibid.: 109).

Finally, in latest research (Yus 2015a, 2015b, 2015c, 2016a), an extension of the RT 
model has been proposed in order to include the analysis non-intended non-propositional effects. These refer to feelings, emotions, impressions, etc. that are not overtly intended by the communicator, but are generated from the act of communication (leaked, as it were), and add (positively) to the cognitive effects derived from discourse interpretation or (negatively) to the mental effort required for processing the utterance. These effects may be assessed consciously by the addressee, or lie beyond his/her awareness, but in any case they influence eventual relevance.

In short, the extended model would cover a broad range of communicated and/or inferred information: speaker-supported propositional content (explicatures, strong implicatures, propositional attitudes, some weak implicatures), hearer-supported weak implicatures (often beyond speaker's overt intentions), speaker-supported non-propositional feelings and emotions (affective attitude), and hearer-supported feelings and emotions beyond the speaker's intentions, that is, non-intended non-propositional effects generated beyond the act of communication but which affect eventual relevance. Consider this example (Sperber and Wilson 2015: 121):

(12) Passenger: What time is the next train to Oxford?

Railway official: 12.48 .

Sperber and Wilson picture the case in which the official has spoken in a neutral tone of voice and with an impersonal facial expression, in which case his meaning could be paraphrased as only the explicit proposition that the next train to Oxford leaves at 12.48. However, if an urgent tone of voice or a warning look on his face is added, and even though his explicit information on train departure would remain the same, part of the intended import would be rather less determinate: he might be implicating, for instance, that the train is about to leave, that the seats are filling up fast, that the platform is further away than the passenger might have thought, that the passenger's estimated walking speed may not be enough to get her there on time, and so on. In that case, his meaning would be partly precise and partly vague. And other effects might be added from this official's utterance plus nonverbal behaviour, for example a number of hearer-centred implicatures (beyond the official's intentions) such as "I will miss the job interview", and also a number of "leaked" nonintended non-propositional effects, for instance on the train reliability, feelings about passenger's colleagues' reaction upon not turning up, or general satisfaction with the punctuality of British trains. Another possible non-intended non-propositional effect might be increased trust towards a friend of the passenger's, who early that morning told him "Ask an official if you like, but I am pretty sure there's a train to Oxford at 12.48", among other possible non-propositional effects beyond the act of communication (but leaked from it).

\section{Affective attitude and intention in ironical acts of communication}

Ironies entail the identification of an echo toward which a dissociative attitude is held. And, as claimed in this paper, a good account of how ironies are interpreted also demands the inclusion of affective attitude ascription in the RT model as an essential component, together with echo and (propositional) dissociative attitude, so that the eventual interpretation is appropriately linked to a humorous, praising, mildly critical or utterly offensive quality, as intended by the speaker. It should be stressed that emotion ascription is also relevance-driven, and the effort demanded for its identification should generate an offset of cognitive reward in exchange. For example, affective attitude ascription from nonverbal behaviour will only be worth the hearer's attention if that inferential operation produces cognitive effects. Many of the speaker's nonverbal behaviours are not intended to produce significant alterations in the 
interpretation of the accompanying text, or are simply exuded beyond the speaker's awareness and are either redundant or do not really alter the interpretation of verbal content. However, on some occasions affective attitude ascription does yield significant changes in the outcome of interpretation, thus becoming relevant in its own right.

Maiese (2014: 524) proposes the term affective framing to capture the idea that even nonintentionally expressed emotions are a matter of active appraisal, and also that bodily affectivity permeates our interpretations and patterns of attention. Affective framing is defined as "a spontaneous, non-inferential, and pre-reflective way of discriminating, filtering, and selecting information that allows us to reduce the overwhelming clutter of information to something first-personally manageable and confer upon it specific cognitive significance". As such, it fits the relevance-driven, discriminating quality of human cognition as a whole (as covered by the wide-ranging cognitive principle of relevance: "Human cognition is geared to the maximisation of relevance"). If we did not rely on affective framing, we would be faced with a potentially endless array of possible cognitive and interpretive options, to which we would have to add the interpretation of feelings and emotions ostensively intended to be spotted and inferred, as is the case in many instances of ironical communication.

Sperber and Wilson (1995: 240) do mention the role of emotions in irony comprehension, stating that speakers use an echoic utterance to convey different attitudes and emotions "ranging from outright acceptance and endorsement to outright rejection and dissociation, and that the recognition of these attitudes and emotions may be crucial to the interpretation process". Sperber and Wilson (ibid.) opt for a picture of continuum, with different blends of attitude and emotion giving rise to a whole range of borderline cases which do not fit neatly into any existing scheme. In my opinion, affective attitude ascription should be incorporated into the RT model of irony comprehension, together with dissociative attitudes and the source of the echo, and the goal of a cognitive pragmatics should be to provide an account of how this affective attitude is spotted and how it influences the comprehension of the propositional content. And this is particularly noticeable in the case of ironical communication. Akimoto et al. (2014: 1168) are right in remarking that

verbal irony implies an underlying emotional attitude that differs from the meaning of what is actually said. Comprehension of irony is a representative example of the high-order sociolinguistic abilities of humans. It goes beyond literal understanding, integrating various types of information from the social context, including events, the speaker's beliefs and emotional attitudes, and paralinguistic cues such as facial expression. [...] Affective aspects are also important because they are not only involved in the processing of emotional interpretive cues, but are also closely related to the social function of irony, which is the reason why irony is used.

Furthermore, there seems to be no incompatibility in holding a propositional attitude towards some event, fact or opinion (echo) and, at the same time, holding an affective attitude towards the same thought or opinion echoed. In fact, they are often tied together. In this sense, Wichmann (2000) comments that a propositional attitude may be affectively neutral, but the kind of labels we associate with it reflect the emotions aroused by that opinion, belief or knowledge. Therefore, labels associated with the expression of propositional attitude seem to be closely allied to those associated with feelings and emotions. Similarly, Gibbs et al. (2002: 142) link propositional and affective attitudes when they underline the fact that irony implies a judgmental attitude with a strong affective, emotional dimension. Irony may, somewhat paradoxically, signal detachment, yet can also reflect deep emotion and evoke a range of affective responses.

By contrast, Wharton (2009) and Strey (2016) propose an alternative way in which propositional attitudes (conveyed verbally) and affective attitudes (conveyed nonverbally) may be combined: an application of the conceptual/procedural distinction (translational vs. 
non-translational in Wharton 2009) to nonverbal behaviours (and, possibly, to the affective attitude encoded by these nonverbal behaviours). Wilson and Serber (1992: 10) summarise this conceptual/procedural dichotomy as follows: "Inferential comprehension involves the construction and manipulation of conceptual representations; linguistic decoding feeds inferential comprehension; linguistic constructions might therefore be expected to encode two basic types of information: concepts or conceptual representations on the one hand, and procedures for manipulating them on the other". Most words encode concepts, but some words give instructions as to how conceptual representations are to be manipulated and hence encode procedural meaning. The notion has mainly been applied to connectives and discourse markers, which constrain the inferential phase by indicating the kind of inferential process that the hearer should go through (hence reducing the eventual overall effort) in the subsequent stretch of discourse. In recent research, the list of procedural items has been extended to cover nonverbal elements such as intonation, which may direct the hearer towards the speaker's feelings and emotions during comprehension, a particularly suitable application to irony comprehension.

In this case, the speaker's nonverbal behaviour guides the hearer not only toward the intended propositional interpretation, but also -presumably- to the speaker's parallel affective attitude (although nonverbal behaviour may be misleading, with some people smiling ostensively while being utterly critical to someone through sarcasm, for instance). ${ }^{5}$ Wilson and Wharton (2005: 436) comment that affective facial expressions and tones of voice provide support for "alterations in the strength or salience of a wide array of conclusions rather than providing strong support for a single, determinate conclusion". In this sense, Strey (2016: 63) points out that nonverbal behaviours (specifically prosody) encode procedures in order to specify what is being conceptually communicated, and they also procedurally point towards the underlying affective attitude. In the case of irony, this affective attitude would be mainly directed at the source of echo towards which a (propositional) dissociative attitude is held.

Of course, when nonverbal behaviour and different choices of utterances are brought together in one single act of communication, the interpretation conveyed may exhibit different types and intensities of feelings and emotions (affective attitude) while producing the irony (see Gibbs et al. 2002):

(13) [One day while parking at work your car splashes mud on Mary. You look at Mary and ask her why her clothes are such a mess. She replies...].

a. Have you noticed that you've just splashed mud on me with your car? [not much information about the extent of her attitude and emotions].

b. [laughing] I'm getting ready for a "wet T-shirt" competition. [irony, dissociative attitude, amusement].

c. [with an angry look and intonation] Thanks a lot for giving me a bath!!! [irony, dissociative attitude, anger].

d. [with a very angry look and very marked intonation] I loooove your driving ability!!! Can you do it again, pleaaaase?

[irony, dissociative attitude, much more anger].

Besides, in Yus (2016a) an example is provided that shows how a person can hold a stable and permanent dissociative attitude towards some fact (and have a strong belief on why this

5. A reviewer of this paper wonders if a nonverbal behaviour such as a sneering smile would itself be a cue to sarcasm (if recognised). I agree. I was simply remarking the fact that the very same smile might well be used for positive (i.e. humorous) and negative or critical intentions (i.e. sarcasm) without variation in its production, thus leaving all the guesswork to the hearer. 
attitude is held) and nevertheless go through different, more transitory affective attitudes towards the target of this attitude (echo) on different occasions depending on contextual constraints:

(14) [Juan has always complained of those politicians who do not care about their appearance or dress inelegantly since, for him, personal appearance and clothing in politics are crucial to achieving the desired election results].

(15) Juan: Have you seen the candidate from the conservative party? I can't believe it.

Luis: Yes, I have...They could have chosen a better candidate...

Juan: [Smiling ostensively] At least he dresses very elegantly and looks really tidy.

Luis: Yes, he is not the best dressed politician, and having a pigtail and that three-day beard does not do him any good either. But you shouldn't be so critical of his appearance. Perhaps it's not so important nowadays, and it's his performance as a politician that counts.

(16) [Juan hopes that a political change will take place in the forthcoming elections. He has become fond of the ideas of the left-wing party candidate, who does not look too tidy, has a three-day beard and a pigtail].

(17) Juan: Have you read the left-wing party's manifesto? I really think these guys could change this country. I like their revolutionary ideas.

Luis: I still haven't had a chance to look at it, but I do think we need a change in this country. The leader says some sensible things about how to tackle the crisis.

Juan: [Smiling ostensively] Nice pigtail and beard, though [laughs].

Luis: Hahaha... Swallow your principles! You'll have to accept this guy's look if you like the ideas of his party.

In both situations, Juan holds a similar attitude within the dissociative range towards the unfulfilled general norm that politicians in should dress smartly and be mindful of their appearance, since personal appearance plays a part in the eventual voters' satisfaction with the party that they represent. In both cases, Juan criticises the leader of a political party ironically for not following this general norm. But the feelings and emotions associated in each case vary. In (14-15), Juan feels angry about the politician's look, and this feeling adds to the default critical connotation of his ironical utterance, even though he is also smiling. By contrast, in (16-17) he still has that dissociative attitude towards an unfulfilled norm, but the feelings associated with this attitude are milder, even close to amusement or a humorous connotation, which is corroborated by Luis' laughter upon hearing Juan's utterance. As a consequence, the same irony, with the same underlying attitude (which Juan has held for quite some time), has different affective attitudes associated with it, which ultimately leads to different interpretations.

In general, it can be stated that, on most occasions, affective attitudes are part of the speaker's intended interpretation and play a role in obtaining eventual relevance and an accurate interpretation from the ironical utterance. They are part of what the speaker expects the interlocutor to recover in order to grasp an appropriate interpretive outcome, to the extent that speakers often get annoyed or puzzled when their feelings and emotions attached to the act of ironical communication are not spotted properly. However, the degree and strength of the speaker's feelings and emotions while engaged in the production of irony are not always easy to spot, as has already been mentioned. This should not entail that these are not important for communication in general and for irony comprehension in particular. Besides, 
the determination of the "intentional vs. exuded" quality of feelings and emotions may also be tricky sometimes. This led Leggitt and Gibbs (2000) to doubt that emotion ascription should play a major part in irony comprehension. They start off with the example of a woman saying ironically "Thanks a lot for giving me a bath" after being splashed by a car, which conveys the strong impression that she is angry, but they wonder whether she intends for listeners to recognise her emotional state as part of her communicative meaning. ${ }^{6}$ In this paper it is claimed that speakers do hold this intention, even if the assessment entails broad qualities of feeling or emotion awareness by speakers and affective attitude ascription by hearers.

Of course, we are constantly conveying, communicating or exuding information about our emotional states, attitudes, evaluations, etc., and, as Lieberman (2000: 111) summarises, several of the nonverbal cues that reflect our internal state can be controlled consciously to a greater or lesser degree, but this will mainly occur if one becomes aware of the process of non-verbal encoding, with additional cues (e.g. tone of voice, blinking, posture) being beyond our full control. We produce part of our nonverbal cues intuitively, without conscious awareness. Arndt and Janney (1991: 538) also comment that it is not always possible to distinguish clearly between conscious emotive displays and unconscious emotional behaviour.

Langlotz and Locher (2013: 95) further assert that emotional cues alone are often not a good indication of the speaker's emotional state and the underlying intention to communicate it, for two reasons. First, emotional cues are often withheld or modulated because of social and cultural norms of display. Second, there is no direct visible link between emotional cues and internal emotional states. Therefore, while some cues may result from spontaneous expressions of genuine emotional states, other cues may be used strategically to emotionalise a given message in the absence of actual arousal. In the case of irony, it is for the speakers' benefit to get a proper humorous, praising, critical interpretation with the aid of affective attitude ascription, even though degrees of control on this continuum from spontaneous to strategic emotional display are very difficult to distinguish.

In a similar fashion, Pickard (2003: 96) focuses of the lack of ability that humans often exhibit when trying to assess their feelings or emotions (and the parallel appropriateness of their communication to others). The intentionality of many emotions differs from the intentionality of cognitive states like judgments or beliefs: "There may be no intentionality in need of explanation. You can just be feeling sad. On the other hand, you may know perfectly well which type of emotion you are experiencing, but neither immediately nor with authority know what the emotion is about" (ibid.).

Besides affective attitude ascription, another problem raised (and already commented upon above) refers to the human ability to infer fine-grained degrees of intensity in feelings and emotions in general, together with an ability to identify subtle variations in the range of possible affective attitudes that may be communicated specifically with an act of ironical communication. I support the claim that humans are indeed able to discriminate different shades of feelings and emotions, but broader categories in the positive-negative continuum of

6. [After being splashed by a car] when Christine says "Thanks a lot for giving me a bath", she conveys the strong impression that she is angry, but does she intend for listeners to recognize her emotional state as part of her communicative meaning? Much work in cognitive science assumes that the expression and understanding of speaker meaning depends on, and is limited by, the recognition of communicative intentions [...] most conversational analysts assume that interpersonal communication consists of the sender intending to cause the receiver to think or do something just by getting the receiver to recognize that the sender is trying to cause that thought or action [...]. Others suggest the need to address non-intentional actions to account for emotions in communication because emotions do not conform to standard assumptions about intentionality. In contrast with language, emotions may be either intentionally or uncontrollably revealed, or they may be present within a person but stifled or not revealed (Leggitt and Gibbs 2000: 4-5). 
affective attitudes should also suffice to lead the hearer in the right direction towards a relevant interpretation of the ironical utterance. As Bromberek-Dyzman (2012: 89-90) acknowledges, "studies of the conceptual organization of emotion support the view that people's knowledge about emotions is hierarchically organized to respect a super-ordinate division between positivity and negativity".

Wharton (2009: 56) holds a similar opinion when he states that hearers can discriminate and interpret subtle variations in tone of voice or facial expression: "We read natural signs much as the engineer studies the needle on an analogue pressure gauge, where the needle's movement is analogous to the rising and falling of the pressure". A frown and angry tone of voice are in a similarly proportional or analogous relationship to the amount of affect the speaker intends to convey. Depending on the gravity of his/her frown and the tone of voice that the speaker uses, the interlocutor can decide whether he/she is mildly annoyed, or quite angry or absolutely furious. The ability to interpret these degrees of annoyance or anger or happiness depends a lot on an inherent ability to discriminate tiny variations in facial expression and tone of voice.

\section{Affective attitude and stages of irony comprehension}

In general, it can be stated that speakers normally intend their affective attitudes to be conveyed as part of what counts as relevant in the ironical act of communication, precisely because eventual interpretations of irony may differ radically depending on this identification. But, at what stage of comprehension are these attitudes spotted and inferred?

RT predicts comprehension as a mutual parallel adjustment of the following cognitive operations made upon every stretch of text being interpreted in a linear sequence:

a. Construct an appropriate hypothesis about explicit content (explicatures) via decoding, disambiguation, reference resolution, and other pragmatic enrichment processes.

b. Construct an appropriate hypothesis about the intended contextual assumptions (implicated premises).

c. Construct an appropriate hypothesis about the intended contextual implications (implicated conclusions, typical case of implicature).

When inferring interpretations from the speaker's utterance, we follow a linear pattern, processing every chunk of text, and each bit of text processed becomes a preliminary context upon which subsequent pieces of text are processed. ${ }^{7}$ Hearers do not wait until the whole utterance is coded to determine its explicit and implicated interpretations. Instead, hearers identify the words of the initial stretch of the utterance (so-called logical form) and access contextual information, extract an explicit interpretation, and perhaps already derive implicatures from this stretch of the utterance. As in all instances of utterance processing, human cognition takes the decoded linguistic meaning and accessible contextual assumptions as evidence for the interpretation, and this interpretation must ultimately be both inferentially sound and consistent with the presumption of optimal relevance (Carston and Hall 2011). Hearers are not expected to first decode the entire utterance, then enrich it inferentially in order to arrive at the explicature, and only then use the explicature, together with contextual assumptions, to form hypotheses about implicatures. Instead, the explicatures, implicatures,

7. "Consider someone about to process some new information. He still has in mind some of the assumptions he has just been processing. People do not come to the processing of new information with a 'blank mind'; they have some kind of short-term memory store (or several such stores, or devices functionally equivalent to shortterm memory stores) whose contents are simply never erased, at least when the individual is awake" (Sperber and Wilson 1995: 138). 
and contextual assumptions are mutually adjusted in parallel until they form an inferentially sound relation, with premises (explicature, contextual assumptions) warranting conclusions (implicatures). It follows that a hypothesis about an implicature can both precede and shape a hypothesis about an explicature. In this paper, the proposal would be to extend this mutual parallel adjustment in order to incorporate the identification and assessment of the speaker's affective attitude towards the opinion, event or utterance to which a (propositional) dissociative attitude is held.

The key to the stage at which the speaker's dissociative attitude is spotted, the affective attitude is inferred and the ironical interpretation is reached lies in how much (and when) the hearer is alerted to the non-explicit, ironical intention of the speaker's with the aid of substantial contextual support (see Yus, 2000a, 2000b, 2009, 2016a, forthcoming). In Yus (2016b), it was claimed that the speed of irony comprehension and the attention paid to the explicit interpretation of its content depend on several constraints. Firstly, on what kind of contextual information is accessed and the degree of incompatibility between that contextual information and the explicit interpretation of the utterance being processed. Secondly, on whether the hearer is capable of accessing information from several sources of contextual information (e.g. general encyclopaedic knowledge, knowledge on the speaker, previous utterances, nonverbal behaviour, etc.). ${ }^{8}$ Thirdly, on whether the access to irony-facilitating contextual information is activated sequentially or simultaneously (for example some information from background knowledge invalidating an explicit interpretation and, at the same time, the identification of the speaker's ostensive nonverbal behaviour invalidating that very same explicit interpretation). Indeed, the human brain is capable of integrating simultaneously incoming information from multiple sources. This integration should lead to a more effective and faster processing of the ironic interpretation. And finally, on how accessible is the information from context is.

In any case, what is clear is that at some stage during the interpretation of the utterance the hearer is alerted to a non-explicit interpretation, which leads to the identification of the irony-related dissociative attitude plus the affective attitude associated with it. In Yus (2016b), a possible explanation of how this occurs is provided, based on a specific type of metarepresentation. The starting point is Wilson's (2009) proposal that we should fine-grain the concept of metarepresentation by identifying three basic types: (1) The mindreading ability or metapsychological ability to represent and think about one's own thoughts and those of others. (2) The pragmatic ability or metacommunicative ability to represent and think about utterances and other overt communicative acts. And (3) the argumentative ability or metalogical ability, which contributes to a more general capacity for epistemic vigilance: the capacity to defend oneself against mistakes or deliberate deception by communicators (epistemic vigilance).

Concerning irony comprehension, Wilson (2009: 219) suggests that it has both an epistemic and a mindreading component, since "the speaker expresses a proposition she regards as false (or epistemically unsound), intending to share with the audience, via the expression of a mocking, sceptical or contemptuous attitude, her opinion of its epistemic status". However, these types of metarepresentation in irony comprehension should also be conceptualised as being activated in a mutual parallel adjustment, just in the same way as context accessibility, determination of explicatures, derivation of implicatures and

8. "[What is] at stake in understating irony is an inferential ability regarding the sender's information (sender's sex, job, personality, speech, relation with the receiver), given social situation, and intent in the context of the situation of his or her speech. The receiver needs the ability to understand the given social situation and to infer therefrom in order to figure out the sender's intent. He or she achieves this by considering the relation between the sender and receiver, detailed situational contexts, and various verbal and non-verbal makers based on the sender's specific information" (Lee 2014: 148-149). 
dissociative attitude ascription. Specifically, this adjustment would be carried out by the interlocutor's pragmatic and argumentative ability within the general cognitive framework of the mindreading ability. ${ }^{9}$

Since the argumentative ability (hard-wired for epistemic vigilance) is the one in charge of detecting contextual inconsistencies, it would also trigger an attitude-tracking inferential activity in the hearer while the utterance is being inferred. In this scenario, it is logical to assume that the argumentative ability is the one alerting the hearer to a mismatch between context and utterance meaning (proposition expressed) while the hearer is engaged in the interpretation of the utterance by using the pragmatic ability. This intuition can be represented as a number of steps:

a. The communicative principle of relevance triggers the hearer's mindreading activity. What the speaker is saying conveys a presumption that it is going to be relevant enough to be worth processing, and hence mindreading is automatically activated.

b. The metacommunicative ability, devoted to a step-by-step extraction of the intended interpretation from decoded content, is activated.

c. With this ability, the hearer decodes the content of the utterance for every chunk of text being processed and engages in a mutual parallel adjustment of explicit content, implicated premises and conclusions (implicatures) and context.

d. The hearer's argumentative or metalogical ability detects some incongruity between the interpretation being selected and the information provided by context, which triggers the search for the attitude that underlies this incongruity (epistemic vigilance).

e. The speaker's dissociative attitude is identified. This is essential for distinguishing it from other types of attitude such as those involved in deception, jokes or lies.

f. The source of the echo is located. As pointed out above, the source of the echo can be broad or specific, directed at an individual or referring to general norms, but all instances of irony involve an echoic quality of the utterance. Further inferencing is devoted to determining the speaker's affective attitude towards this source of echo, which is essential to determine the kind of interpretation that the speaker intends to convey with the irony (offense, criticism, humour, praise, etc.). As was exemplified above, propositional content and affective attitude are intertwined and mutually influence each other (Moeschler 2009: 460).

g. The intended ironical interpretation is obtained (implicature), which differs, to a greater or lesser extent, from the explicit interpretation of the utterance.

Concerning step (d) above, for irony the two main sources on the basis of which the hearer is able to spot incongruity between the explicit interpretation of the utterance and contextual information are the speaker's vocal and visual nonverbal behaviour and the information on the speaker available to the hearer (mutually manifest assumptions on the speaker's likes, dislikes, beliefs, habits, etc.). The latter is worth commenting in some detail. The key to determining the affective attitude that speaker holds (humorous, offensive, praising...) is often the retrieval of information about how intensely the dissociative attitude towards the source of the echo is felt, and this entails accessibility to a wide array of assumptions about the speaker. The question, at this point, is how hearers are able to select from context only the assumptions regarding the speaker that play some part in the determination of propositional and affective attitudes. In Yus (2016b) the term narrowed mutual cognitive environment is proposed as an answer. The idea is that when we interact with people that we know (e.g. friends), not all the information belonging to both interlocutors' mutual cognitive environment is equally accessible. Some information is repeatedly talked about and accessed recurrently in the course of conversations with these

9. Sperber et al. (2010: 360) point out that "the abilities for overt intentional communication and epistemic vigilance must have evolved together, and must also develop together and be put to use together." 
interlocutors, thus acquiring certain prominence or salience. ${ }^{10}$ Similarly, Aune (1997) comments how emotions are easier to infer when interlocutors know each other and have constructed a readily accessible archive, as it were, of emotion expression. In this sense, longer-term relational partners seem to converge in their ratings of each other's emotion experience and expression. This convergence may arise from the information and feedback they obtain on their judgments and emotional expressions through repeated interactions with each other. And Rostomyan (2012: 290) adds the positive or negative predisposition of interlocutors. This stems from their social relationships, as well as the nature of the formerly experienced emotions, and enables interlocutors to interpret the encoded message as emotionally positive or negative without even tracing any explicit verbal elements expressing emotive charge.

Therefore, it saves a great deal of effort when inconsistencies between the ironical utterance and information on the speaker are found within this narrowed mutual cognitive environment, which would include these assumptions which are very salient or prominent, and are almost unconsciously activated due to frequent interactions with the interlocutor, where this information has repeatedly been mentioned or commented upon. This narrowed environment may also include information about the interlocutor's beliefs, habits, likes, etc. (and the extent of the attitudes held toward them by the speaker), together with a store of information about individual-specific nonverbal behaviours, also saving effort when determining the affective attitude involved and the intentionality (or lack of it) in its communication.

\section{Concluding remarks}

RT makes specific claims about irony: (a) it is echoic (i.e., it implicitly expresses the speaker's attitude to the beliefs being represented in the irony); and (b) the attitude involved in the echo is one of dissociation from the thoughts being echoed (Curcó 2000: 261). In this paper, it has been claimed that these ingredients are not enough to provide a detailed account of how ironies are interpreted and why the same ironic utterance might end up being entertained as humorous, mildly critical, utterly offensive or praising. The proposal in this paper is to add to these two elements of irony comprehension the need to identify the speaker's parallel affective attitude towards the source of the echo. In a nutshell, if the speaker has a certain dissociative (propositional) attitude towards this source of the echo, the (non-propositional) affective attitude would cover how this source of echo makes the speaker feel, what emotions are stirred. This addition to the RT model of irony comprehension allows us to explain the specific inferential outcomes of irony comprehension, ranging from amusement, mild criticism, offense or praise, among others.

\section{Acknowledgements}

This research was supported by EMO-FUNDETT research project, a coordinate project funded by the Spanish Ministerio de Economía y Competitividad (FFI2013-47792-C2-1-P).

\section{References}

Akimoto, Y., Sugiura, M., Yomogida, Y., Miyauchi, C.M., Miyazawa, S. and Kawashima, R.

10. Palmer and Simmons (1995) propose the roughly similar term mental model, supposed to be instantiated in each interlocutor's working memory. This model contains a variety of information at various levels of abstraction, including affective information about the feelings held by the actor, general knowledge about the type of social situation, specific knowledge about the conversational partner, group affiliation, and episodic information about past experiences with the partner. 
2014. "Irony comprehension: Social conceptual knowledge and emotional response". Human Brain Mapping 35: 1167-1178.

Arndt, H. and Janney, R.W. 1991. "Verbal, prosodic, and kinesic emotive contrasts in speech". Journal of Pragmatics 15: 521-549.

Aune, K.S. 1997. "Self and partner perceptions of the appropriateness of emotions". Communication Reports 10(2): 133-142.

Bromberek-Dyzman, K. 2012. “Affective twist in irony processing”. Humana.Mente 23: 83111.

Caffi, C. and Janney, R.W. 1994. "Toward a pragmatics of emotive communication". Journal of Pragmatics 22: 325-373.

Carston, R. and Hall, A. 2011. "Implicature and explicature". In H-J. Schmid and D. Geeraerts (eds), Cognitive Pragmatics. Berlin: Mouton de Gruyter, 47-84.

Curcó, C. 2000. "Irony: Negation, echo and metarepresentation". Lingua 110: 257-280.

Fussell, Susan R. 2002. "The verbal communication of emotion: Introduction and overview". In S.R. Fussell (ed), The Verbal Communication of Emotions. Interdisciplinary Perspectives. Mahwah: L.E.A., 1-15.

Garmendia, J. 2010. "Irony is critical". Pragmatics \& Cognition 18(2): 397-421.

Gibbs, R.W., Leggitt, J.S. and Turner, E.A. 2002. "What's special about figurative language in emotional communication?" In: S.R. Fussell (ed), The Verbal Communication of Emotions. Interdisciplinary Perspectives. Mahwah: L.E.A., 125-149.

Gutt, E.-A. 2013. "Gutt, E.-A. 2013. How does the affective relate to ostensive-inferential communication?" Draft.

Hess, U. 2001. "The experience of emotion: Situational influences on the elicitation and experience of emotions". In A. Kaszniak (ed), Emotions, Qualia, and Consciousness. Singapore: World Scientific Publishing, 386-396.

Langlotz, A. and Locher, M.A. 2013. "The role of emotions in relational work". Journal of Pragmatics 58: 87-107.

Lee, J.O. 2014. "Communication mechanism of ironic discourse". Advanced Science and Technology Letters 52: 147-152.

Leggitt, J.S. and Gibbs, R.W. 2000. "Emotional reactions to verbal irony". Discourse Processes 29(1): 1-24.

Lieberman, M. 2000. "Intuition: A social-cognitive neuroscience approach". Psychological Bulletin 126; 109-137.

Maiese, M. 2014. "How can emotions be both cognitive and bodily?" Phenomenology and the Cognitive Sciences 13: 513-531.

Moeschler, J. 2009. "Pragmatics, propositional and non-propositional effects: Can a theory of utterance interpretation account for emotions in verbal communication?" Social Science Information 48(3): 447-464.

Olsson, A. and Ochsner, K.N. 2007. "The role of social cognition in emotion". Trends in Cognitive Sciences 12(2): 66-71.

Palmer, M.T. and Simmons, K.B. 1995. "Communicating intentions through nonverbal behaviors". Human Communication Research 22(1): 128-160.

Pickard, H. 2003. "Emotions and the problem of other minds". In A. Hatzimoysis (ed), Philosophy and the Emotions. Cambridge: Cambridge University Press, 87-103.

Pilkington, A. 2000. Poetic Effects. A Relevance Theory Perspective. Amsterdam and Philadelphia: John Benjamins.

Piskorska, A. 2012. "Cognition and emotions -Jointly contributing to positive cognitive effects?" In A. Piskorska (ed.), Relevance Studies in Poland, Vol. 4. Essays on language and communication. Warsaw (Poland): WUW, 102-111.

Planalp, S. 1999. Communicating Emotion. Social, Moral, and Cultural Processes. 
Cambridge: Cambridge University Press.

Rostomyan, A. 2012. "The vitality of emotional background knowledge in court". Pólemos 6(2): 281-292.

Sperber, D., Clément, F., Heintz, C., Mascaro, O., Mercier, H., Origgi, G. and Wilson, D. 2010. "Epistemic vigilance". Mind \& Language 25(4): 359-393.

Sperber, D. and Wilson, D. 1981. "Irony and the use-mention distinction". In P. Cole (ed), Radical Pragmatics. New York: Academic Press, 295-318.

Sperber, D. and Wilson, D. 1995. Relevance: Communication and Cognition (2nd edition). Oxford: Blackwell.

Sperber, D. and Wilson, D. 2015. "Beyond speaker's meaning". Croatian Journal of Philosophy XV(44): 117-149.

Strey, C. 2016. The Language of Emotions: An Ostensive-Inferential Study. PhD Thesis. Porto Alegre: PUCRS.

Wharton, T. 2009. Pragmatics and Non-Verbal Communication. Cambridge: Cambridge University Press.

Wichmann, A. 2000. "The attitudinal effects of prosody, and how they relate to emotion". Paper delivered at ISCA Workshop on Speech and Emotion. University of Belfast, September.

Wilson, D. 2006. “The pragmatics of verbal irony: Echo or pretence?”. Lingua 116: 17221743.

Wilson, D. 2009. "Irony and metarepresentation". UCL Working Papers in Linguistics 21: $183-226$.

Wilson, D. 2013. "Irony comprehension: A developmental perspective". Journal of Pragmatics 59(A): 40-56.

Wilson, D. and Sperber, D. 1992. “On verbal irony”. Lingua 87: 53-76.

Wilson, D. and Wharton, T. 2005. "Relevance and prosody". UCL Working Papers in Linguistics 17: 427-454.

Yus, F. 2000a. "On reaching the intended ironic interpretation". International Journal of Communication 10(1-2): 27-78.

Yus, F. 2000b. "Literal/nonliteral and the processing of verbal irony". Pragmalingüística 89: 349-374.

Yus, F. 2009. "Saturación contextual en la comprensión de la ironía". In L. Ruiz Gurillo and X. Padilla García. Frankfurt (eds), Dime cómo ironizas y te diré quién eres: Una aproximación pragmática a la ironía. Frankfurt: Peter Lang, 309-331.

Yus, F. 2015a. "Should relevance theory analyse what is non-propositional, non-intentional but yet affects the eventual relevance?" Paper delivered at Relevance Round Table Meeting 4. Kraków: Institute of English Studies, Jagiellonian University of Kraków, September.

Yus, F. 2015b. "The discursive management of the phatic Internet (and how to explain it pragmatically)". Paper delivered at Approaches to Digital Discourse Analysis (ADDA). Valencia (Spain), November.

Yus, F. 2015c. "Broadening the (propositional) scope of pragmatics in order to address the (non-propositional) quality of humorous effects". Paper delivered at I Workshop on Advanced Studies of Humor and Gender (WASHUM). Alicante (Spain): University of Alicante, November.

Yus, F. 2016a. Humour and Relevance. Amsterdam and Philadelphia: John Benjamins.

Yus, F. 2016b. "Relevance theory and contextual sources-centred analysis of irony. Current research and compatibility". In M. Padilla Cruz (ed), Relevance Theory: Recent Developments, Current Challenges and Future Directions. Amsterdam and Philadelphia: John Benjamins. 